\title{
Burned forest characterization at single-tree level with Airborne Laser Scanning for assessing wildlife habitat
}

\author{
Ángeles Casas ${ }^{1}$, Mariano García ${ }^{2,3}$, Rodney B. Siegel ${ }^{4}$, Alexander \\ Koltunov $^{1,5}$, Carlos Ramírez ${ }^{5}$, and Susan Ustin ${ }^{1}$ \\ ${ }^{1}$ Department of Land, Air and Water Resources, One Shields Avenue, \\ University of California, Davis, USA \\ ${ }^{2}$ University of Leicester, Centre for Landscape and Climate Research, \\ University Road, Leicester, LE1 7RH, UK \\ ${ }^{3}$ Jet Propulsion Laboratory, California Institute of Technology, \\ Pasadena, CA 91109, USA \\ ${ }^{4}$ The Institute for Bird Populations, Point Reyes Station, California, \\ USA \\ ${ }^{5}$ USDA Forest Service, Region 5 Remote Sensing Lab, McClellan, \\ California, USA
}

\section{Abstract}

Abundance, size, and spatial distribution of standing dead trees (snags), are key indicators of forest biodiversity and ecosystem health. These metrics represent critical habitat components for various wildlife species of conservation concern, including the Black-backed Woodpecker (Picoides arcticus), which is strongly associated with 
recently burned conifer forest. We assessed the potential of Airborne Laser Scanning (ALS) to detect and characterize conifer snags and identify Black-backed Woodpecker habitat using previously derived empirical thresholds of conifer snag basal area. Over the footprint of the Rim Fire, a megafire that extended ( 104,000 ha) through a heterogeneous mosaic of conifer forests, oak woodlands, and meadows in the Sierra Nevada mountains of California, we identified conifer snags and estimated their basal area from single-tree ALS-derived metrics using Gaussian processes in four major steps. First, individual trees were mapped using the Watershed Segmentation algorithm, resulting in $87 \%$ detection of trees with stem diameter larger than $30 \mathrm{~cm}$. Second, the snag/live classification model identified snags with an overall accuracy of $91.8 \%$, using the coefficient of variation of height and intensity together with maximum intensity and fractional cover as the most relevant metrics. Third, the conifer/hardwood snag classification model utilizing the maximum height, median height, minimum intensity, and area metrics separated snag forest types with an overall accuracy of $84.8 \%$. Finally, a Gaussian process regression model reliably estimated conifer snag stem diameter $\left(R^{2}=0.81\right)$ using height and crown area, thus significantly outperforming regionally calibrated conifer-specific allometric equations. As a result, $\sim 80 \%$ of the snag basal area have been mapped. Optimal and potential habitat for Black-backed Woodpecker comprise $53.7 \mathrm{~km}^{2}$ and $58.4 \mathrm{~km}^{2}$, respectively, representing 5.1 and $5.6 \%$ of the footprint of the Rim Fire. Our study illustrates the utility of high-density ALS data for characterizing recently burned forests, which, in conjunction with information about the habitat needs of particular snag-dependent wildlife species, can be used to assess habitat characteristics, and thus contribute 
greatly to forest management and biodiversity conservation.

Keywords: Gaussian Processes, Watershed Segmentation, Single-tree level, Stem Diameter, Basal Area, Megafire, Wildlife Habitat, Black-backed Woodpecker, Airborne Laser Scanning, LiDAR, Snags, Dead trees, Rim Fire. 


\section{Introduction}

2 Standing dead trees (snags) are key indicators of forest biodiversity and ecosystem

3 health (Siitonen, 2001; Noss et al., 2006; Moritz et al., 2014). They constitute a crit-

4 ical component of habitat for many rare and specialized wildlife species (Siitonen,

5 2001; Bütler et al., 2004). The lack of spatially distributed data on snag abundances,

6 types, and distributions has been identified as a major constraint on the predictive

7 capacity of occupancy and distribution models for snag-dependent wildlife species, s including woodpeckers (Bütler et al., 2004; Martinuzzi et al., 2009; Müller and Bütler, 9 2010; Vogeler et al., 2014; Tingley et al., 2014, 2015). Woodpeckers fulfill a keystone

function in conifer forests as primary cavity excavators whose cavities are subsequently used by numerous other species for roosting, nesting, and concealment from predators (Daily et al., 1993; Tarbill et al., 2015). Increasing size and frequency of forest fires in temperate forests resulting from climate change (Flannigan et al., 2009; Miller et al., 2009; Stephens et al., 2013) will only exacerbate the need for detailed, accurate mapping of snags in burned areas to inform decisions about post-fire forest management and biodiversity conservation.

Since the key role of forest physiognomy in wildlife habitat was established (MacArthur and MacArthur, 1961) it has been used to explain species occurrence and overall diversity (Farley et al., 1994). Airborne Laser Scanning (ALS) capability to characterize detailed vertical and horizontal structural patterns across broad areas has been successfully applied to advance wildlife habitat modeling (Mason et al., 2003) and assess wildlife-habitat relationships (Davenport et al., 2000; Bradbury et al., 2005). 
On the one hand, ALS data can be used as an exploratory tool to better understand resource selection by species of known distributions (Goetz et al., 2007; Clawges et al., 2008; Smart et al., 2012; Garabedian et al., 2014; Ackers et al., 2015). However, ALS data also can be used to delineate habitat suitability, through mapping of habitat features known to be important for target species (Mason et al., 2003; Nelson et al., 2005; Hyde et al., 2006; Swatantran et al., 2008; Martinuzzi et al., 2009; Graf et al., 2009). Basal area, which is closely related to biomass (Bergen et al., 2009) is a common measure of tree cover used in wildlife habitat studies (Cade, 1997). While not directly measured by ALS, basal area can be derived from ALS data. Although often critical for predicting or assessing habitat suitability for wildlife, stem diameter and basal area are not generally available at the landscape scale. This is particularly troublesome in the case of burned forests where wildlife occupancy and habitat relationships for snag-dependent wildlife species are commonly defined as a function of snag basal area (Martinuzzi et al., 2009; Tingley et al., 2014).

In recent years, some studies have attempted to use ALS in relation to dead or dying trees for applications such as estimation of dead biomass or carbon storage (Kim et al., 2009; Ferster et al., 2009), forest health or successional stage estimation (Bater et al., 2009; Bright et al., 2013), and wildlife habitat studies (Martinuzzi et al., 2009). A relation between ALS-derived height metrics and dead trees has been found using a plot-based approach with varying results (Solberg et al., 2006; Sherrill et al., 2008; Pesonen et al., 2009; Bater et al., 2009; Martinuzzi et al., 2009), whereas other studies have shown LiDAR intensity data provides an effective predictor of dead trees (Kim et al., 2009; Hudak et al., 2012; Bright et al., 2013). At the single-tree 
level, the use of intensity has been explored in ALS with discrete returns (Korpela et al., 2010; Wing et al., 2015) and full-waveform (Yao et al., 2012). Korpela et al. (2010) show that dead, defoliated trees have approximately 40-60\% lower intensity than living trees. Kim et al. (2009) used plot-based density distributions of intensity values rescaled to 8-bit (0-255) in a mixed coniferous forest and interpreted the lower peak in the bimodal distribution as the presence of snags. With a single-tree approach, Yao et al. (2012) successfully identified snags in a mixed mountain forest using full waveform ALS with $73 \%$ and $71 \%$ of overall accuracy for leaf-on and leafoff condition, respectively. Interestingly, their intensity metrics were shown to be irrelevant for discrimination of dead and live trees; instead the outer geometry of the crown was found to be relevant (Yao et al., 2012). Recently, Wing et al. (2015) presented a point-wise snag filtering algorithm based on point location attributes, neighborhood intensity values, and point density statistics. In that method, tree segmentation and characterization was only applied to points that were first classified as snag points. Also, the method was applied to forests with different conditions, and therefore snag detection rates depended on snag size (Wing et al., 2015).

While the estimation of the stem diameter using ALS is a field of active research given its relation with biomass, growth, tree volume, and biodiversity factors (Popescu and Hauglin, 2014; Maltamo and Gobakken, 2014), only a few studies have attempted to estimate stem diameter and/or basal area of dead trees using a plot-based approach (Pesonen et al., 2008, 2009; Martinuzzi et al., 2009; Bright et al., 2013). Pesonen et al. $(2008,2009)$ first attempted to estimate standing dead wood with poor results. Bright et al. (2013) predicted dead basal area and \% dead basal area in different 
coniferous forests affected by beetle infestation with limited success. Martinuzzi et al. (2009) successfully characterized the forest structure in terms of percentage of snags and DBH classes known to be relevant for various wildlife species to delineate patterns of wildlife habitat suitability in a mixed-conifer forest. Their study makes use of heights and topographic data to derive area-based DBH classes at a $20 \mathrm{~m}$ pixel resolution, showing important improvements when supplementary forest successional data are used (Martinuzzi et al., 2009). Nevertheless, despite the importance of snags in forest management and biodiversity conservation, little attention has been paid to the detection and characterization of snags using ALS data for habitat mapping applications (Martinuzzi et al., 2009; Vogeler et al., 2014, 2015). We know of no previous example of individual snag detection and characterization (type and size) using ALS data to map potential habitat for snag-dependent wildlife species.

This study explores the use of ALS for characterizing burned forest in relevant terms for predicting wildlife habitat quality on the Rim Fire, a megafire that took place in 2013 in the Sierra Nevada mountains of California, creating large patches of mediumand high-severity burned forest. To illustrate the utility of ALS-derived snag characterization for forest planners and wildlife managers, we apply it to map potential and optimal habitat across the fire footprint for Black-backed Woodpecker (Picoides arcticus). This species has been designated by the US Forest Service as a Management Indicator Species (MIS) for snags in recently burned forest across ten National Forests in California. Retaining adequate habitat for this species has been a contentious issue in post-fire forest management efforts at the Rim Fire and other recent fires across the Sierra Nevada region. Black-backed Woodpecker populations in Cal- 
ifornia, Oregon, and the Black Hills of South Dakota are also currently under review for federal listing as threatened or endangered. Our objective is to evaluate the use of ALS data:

1. to map individual conifer snag characteristics (type and size) across a recently burned forest, and

2. to identify patches of potential habitat for a wildlife species known to be dependent on those characteristics.

\section{Methodology}

\subsection{Study site}

The study site comprises the footprint of the 2013 Rim Fire, which burned $\sim 104,000$ ha across portions of Yosemite National Park, Stanislaus National Forest, and adjacent private lands in the Sierra Nevada Mountains of California (Figure 2). The area is topographically complex, with elevations ranging from 60 to $2400 \mathrm{~m}$. The fire burned through a mosaic of vegetation types, including low-elevation (1000 - $1500 \mathrm{~m})$ grasslands, chaparral, and foothill-oak woodland habitat, mainly blue oak (Quercus douglasii Hook. \& Arn) and interior live oak (Quercus wislizeni A. DC. (Fagaceae)); and in the lower montane zone through conifer forests dominated by ponderosa pine (Pinus ponderosa Lawson and C. Lawson). Mixed conifer forests dominate the mid elevation (1500 - $2100 \mathrm{~m})$, including Douglas fir (Pseudotsuga menziesii (Mirb.) 
111

Franco), incense cedar (Calocedrus decurrens (Torr.) Florin), ponderosa pine (Pinus ponderosa Lawson and C. Lawson), sugar pine (Pinus lambertiana Douglas) and Sierra white fir (Abies concolor (Gord. \& Glend.) Lindl. ex Hildebr. var.lowiana (Gord. \& Glend.) Lemmon), Jeffrey pine (Pinus jeffreyi Balf) and California black oak (Quercus kelloggii Newberry). White fir, red fir (Abies magnifica A. Murr.), western whitebark pine (Pinus albicaulis), and limber pine (Pinus flexilis) occur in higher elevation $(\geq 2100 \mathrm{~m})$ portions of the affected area.

\subsection{Black-backed Woodpecker habitat assessment}

We identified and classified Black-backed Woodpecker habitat based on information provided by Tingley et al. (2014), who used radio-telemetry to delineate Black-backed Woodpecker habitat home ranges in three other recently burned forest areas in California, and then described habitat attributes across those home ranges. Tingley et al. (2014) found that the primary driver of home-range size, and, by extension, density of Black-backed Woodpecker pairs across the landscape, was average basal area of conifer snags. Among individual woodpeckers whose home ranges were primarily or entirely within burned areas, the lowest observed value for average snag basal area across the home range was $17.4 \mathrm{~m}^{2} / \mathrm{ha}$, and the mean value was $25.5 \mathrm{~m}^{2} / \mathrm{ha}$. We consider these thresholds the best available criteria for indicating potential and optimal Black-backed Woodpecker habitat, respectively, within our study area. 


\subsection{Field plot data}

We stratified plot locations by forest structure, status (dead/live), and type (hardwood/conifer) within the Rim Fire and an additional $2 \mathrm{~km}$ unburned buffer zone where ALS data were available. To stratify, we used a Landsat-based pre-fire vegetation map (CALVEG www.fs.fed.us) and a burn severity map provided by the U.S. Forest Service (Figure 2). We assessed 147 10-m radius field plots in October 2014; 80 plots were within the footprint of the Rim Fire and 65 plots were within the 2 $\mathrm{km}$ buffer (Figure 2). For every tree with a stem diameter $\geq 10 \mathrm{~cm}$, we recorded status, species, location, and stem diameter and height. Field plot center positions were measured using differential GPS and corrections were applied using the closest fixed antenna for position accuracy, which varied from $0.10 \mathrm{~cm}$ to $0.5 \mathrm{~m}$. Each tree was located by its distance and bearing to center of the plot. For each plot, we calculated basal area, $\left(\mathrm{BA}, \mathrm{m}^{2} / h a\right)$, number of trees per plot $(\mathrm{N})$, and basal area-weighted mean tree diameter, $\left(D_{b w}, \mathrm{~cm}\right)$. BA $\left(m^{2} / h a\right)$ was estimated as the cross-sectional area of an individual tree at breast height (1.3 $\mathrm{m}$ above the ground) and $D_{b w}$ as $\sum_{j=1}^{N}\left(B A_{j} \cdot D B H_{j}\right) / \sum\left(B A_{j}\right)$. The basal area of plots ranged from 2.8 to $162 \mathrm{~m}^{2} / \mathrm{ha}$ with a mean of $47.7 \mathrm{~m}^{2} / \mathrm{ha}$. The minimum and maximum number of trees per plot was 1 and 81 respectively, with a mean of 14 . Overall, we measured 2067 trees, out of which 917 were alive with DBH values ranging from 10 to $155.8 \mathrm{~cm}$, and 1149 were dead with DBH ranging from 10 to $163.2 \mathrm{~cm}$. In addition, the mean DBH and standard deviation for measured conifer and hardwood snags were $29 \pm$ 17 and $28.3 \pm 19.1$ respectively, with small trees outnumbering larger ones. Within conifers snags, there were 657 snags with DBH between 10 and $30 \mathrm{~cm}, 240$ snags 
with $\mathrm{DBH}$ between 30 and $60 \mathrm{~cm}$ and 88 snags with $\mathrm{DBH}$ larger than $60 \mathrm{~cm}$.

\subsection{Overview}

The data analysis workflow consisted of several steps, presented in Figure 1. First, we isolated individual trees using the Watershed Segmentation algorithm initialized with local maxima of the canopy height surface (Sect. 2.6). For each detected tree, we then derived a group of ALS metrics used in the subsequent steps (Sect. 2.7). Then, trees were classified into snags/live categories using a Gaussian processes-based algorithm and the derived metrics (Sect. 2.8.2). Next, we applied the same Gaussian process classifier to separate conifer from hardwood snags as discussed in Section 2.8.2. In the last step, we estimated the stem diameter and basal area of the detected conifer snags, using a Gaussian process-regression model (Sect. 2.8.1). Conifer snag basal area estimation combined with thresholds obtained from a telemetry study of Blackbacked Woodpeckers in burned forest (Tingley et al. 2014) enabled the habitat mapping as described in Sections 2.2.

\subsection{ALS data acquisition and preprocessing}

ALS data were collected in November 2013 by the National Center for Airborne Laser Mapping (NCALM) using an Optech Gemini Airborne Laser Terrain Mapper (ALTM) instrument that recorded up to four returns per pulse. The collected data covered the fire burn area plus a 2-km buffer, with a scan angle of \pm 14 and a nominal $50 \%$ overlap between flight lines, yielding an average pulse density of 19 per $\mathrm{m}^{2}$. We 
normalized heights with the 1-m resolution digital elevation model (DEM) developed by NCALM. In addition to the height information, the intensity was also recorded. Intensity is the ratio of power returned to power emitted (Kaasalainen et al., 2007). The instrument operates in the near infrared region at a wavelength of $1064 \mathrm{~nm}$, and therefore the return intensity provides information about object properties related to the reflectivity at this wavelength. However, it is also function of the illuminated area of the object, scattering from the target, incident angle, proportion of the pulse remaining after previous returns, but primarily the sensor-target distance, or range (Brandtberg, 2007; Höfle et al., 2008; Korpela et al., 2010). Therefore, intensity necessitates a range normalization that provides the intensity values that would have been recorded if all the points were at the same range, i.e. eliminates path length variations (Holmgren and Persson, 2004). We used the normalization method, detailed in García et al. (2010), based on the following equation: $I_{n}=I \cdot R^{2} \cdot R_{s}{ }^{-2}$, where $I_{n}$ is the normalized intensity, $I$ is the original intensity, $R$ is the range and $R_{s}$ is a user-defined standard range, in our case $1000 \mathrm{~m}$.

\subsection{Tree detection}

As shown in Figure 1, the tree detection consists of two main steps. First, the ALS points are converted into a smoothed canopy height model (CHM) with pixel size 0.5 $\mathrm{m}$, which is a sufficiently high resolution to represent the canopy variability. Second, the CHM surface is segmented into regions representing individual trees. To generate a Canopy Height Model (CHM), we used normalized ALS heights from all returns 
and found the maximum height within a radius of the pixel size multiplied by the square root of two. This radius was applied instead of the pixel size to reduce the size of gaps in the initial CHM. We further applied a one-iteration anisotropic diffusion filter (Perona and Malik, 1990) to smooth the CHM while preserving the edges, a critical step to avoid merging canopy crowns in the filtering process. One iteration was chosen to retain the height variability in the CHM while smoothing the crown. To identify individual trees in the second step, we applied a local maxima detection to the smoothed CHM by searching in eight-connected neighborhood pixels with higher values than their external boundary neighbors. These are considered the tops of potential trees. Then, we applied the Watershed Segmentation algorithm (Beucher and Lantuéjoul, 1979) upon the inverted smoothed CHM using local maxima previously detected as initial seeds. The output of the segmentation is a raster with a unique tree label. At this point, segments with maximum heights less than four meters were eliminated, which were considered as maxima of understory or trees with stem diameters smaller than $10 \mathrm{~cm}$, for which we were not interested. This relation was estimated from Sierra Nevada site specific height-DBH allometric equations (Keyser and Dixon, 2008). Given the low accuracy of the positioning, we used field-corrected references to verify the algorithm performance. The adjustment was applied when the ALS-detected tree and the field location were within a distance of $3 \mathrm{~m}$ and differences in height were less than $1 \mathrm{~m}$. To evaluate tree detection, we segregated the test trees into three stem diameter classes given the Black-backed Woodpecker preference for medium to large snags (Dudley et al., 2012; Rota et al., 2014) for foraging, and the lower contribution of small trees to estimated basal area. Following the Califor- 


\subsection{ALS metrics}

For each tree segmented, ALS points higher than two meters were extracted, considering that lower points represent understory, and segments with less than ten points were eliminated. Twenty-five metrics were calculated using normalized heights and intensities (Table 1) for each tree, categorized by height, intensity, crown shape, and porosity. In addition, we estimated area and volume of each tree to describe its crown shape. We calculated the crown area as the area of the vertical projection of the crown, approximated using the convex hull of the returns located within each segment, and the volume as the product of the area by the vegetation layer height (i.e. tallest height within the segment minus the two meter canopy threshold). Furthermore, we quantified the porosity of the crown through the fractional cover, as the proportion of canopy hits within the vegetation layer in relation to all hits within the segment (Riaño et al., 2004). We calculated minimum, maximum, mean, median, mode, standard deviation, variance, coefficient of variation, skewness, and kurtosis for height and intensity values of returns above two meters, to account for the canopy structure, based on the distribution, dispersion, and shape of the returns. Finally, to account for the variability of the point density within the study area, we calculated an accumulated intensity value normalized by density within the segment (García 
et al., 2010) as follows:

$$
\text { cumCorr }=\sum_{i=1}^{n} I_{n} \cdot \frac{\bar{d}_{\text {flight }}}{d_{\text {tree }}}
$$

where $\sum_{i=1}^{n} I_{n}$ is the accumulated normalized intensities, $\bar{d}_{f l i g h t}$ is the mean point density for the whole dataset and $d_{t r e e}$ is the point density of the tree, estimated as the number of returns by the area of the projected crown.

\subsection{Tree classification and DBH estimation using Gaussian processes and ALS-derived metrics}

A Gaussian process (GP) is defined as an infinite collection of random variables, any finite subset of which has a joint Gaussian distribution (Rasmussen and Williams, 2006). As mentioned in sect. 2.4, we applied a GP approach to solve two twoclass classification problems, dead/live and conifer/hardwood, using the 25 ALSderived metrics described in sect. 2.7 and to estimate DBH of dead conifer trees from two ALS metrics: height and crown area. To evaluate performance of our tree classification and DBH estimation methods we used a standard Leave-p-Out (LPO) cross-validation technique. We generated 100 random partitions of the data into training (70\%) and test (30\%) subsets and calculated the respective algorithm performance statistics for each partition. First, we discuss the DBH estimation by the Gaussian process regression that we find conceptually simpler than the GP-based classification approach discussed in sect. 2.8.2. 


\subsubsection{DBH estimation}

In a generic form, the regression model for estimating tree $\mathrm{DBH}$ from a vector of ALS-derived metrics, e.g. height and crown area, can be written as

$$
d=f(x)+\varepsilon
$$

where $d$ is the DBH value for a tree with the ALS metrics in vector $x$, function $f$ is an unknown underlying observation process model; and $\varepsilon$ represents noise and/or unmodeled factors.

In the GP-based formulation of the regression problem, the DBH of an individual tree is considered a normally distributed random variable, and not a single unknown deterministic quantity, as e.g. in a classic regression analysis. We further assume that for any tree group, the joint probability distribution of their DBH is a multivariate normal distribution. Thus collectively, the actual DBH for all trees in the study site can be viewed as a finite sample from a Gaussian stochastic process $f$, with mean function $m(x)$ and a covariance function $K\left(x, x^{\prime}\right)$, commonly called a kernel.

If functions $m$ and $K$ were known, then for any test tree with input ALS metrics in vector $x *$ the true parameters of the normal distribution for the $\mathrm{DBH} d *$ would also be known and could be used to predict the most likely DBH value and derive the prediction error estimates. In reality however, $m$ and $K$ are never known, and therefore need to be estimated based on the following three types of information:

1. available training samples for which both the feature vector $x$ and the output 
2. assumptions about a parametric form of the covariance function $K$, which controls for the GP model complexity; and

3. assumptions about the noise term $\varepsilon$.

Our training samples included of $N_{t r}=396$ conifer snags located and measured during the field campaign, and described in sect. 2.3. Their DBH values range from 10 to $160 \mathrm{~cm}$, with mean $45.2 \mathrm{~cm}$ and the std $24.6 \mathrm{~cm}$. Furthermore, we chose the covariance function required by item 2) to be a squared exponential kernel $K\left(x, x^{\prime}\right)$ :

$$
K\left(x, x^{\prime}\right)=\sigma^{2} \exp \left[-\frac{1}{2} \sum_{p=1}^{P} w_{p}\left(x_{i p}-x_{i p}^{\prime}\right)^{2}\right]
$$

with $(P+1)$ free parameters: $\sigma, w_{1}, \ldots, w_{P}$. Parameter $\sigma$ is the unknown standard deviation of a noise-free DBH signal that properly scales the covariances; $\sigma_{n}$ is the standard deviation of the noise; and $w_{1}, \ldots, w_{P}$ are non-negative weights defining the similarity measure in the P-dimensional metric space. When the input ALS metrics are similarly scaled, their weights also provide a relative measure of relevance for modeling the output DBH. Our original ALS-derived metrics, however, had very different scales, and therefore were normalized into the range between 0 and 1. Finally, the noise term was assumed to take the simplest form. Specifically, for each tree and for each feature the noise was assumed to be independent and identically distributed according to a normal distribution $\mathcal{N}\left(0, \sigma_{n}\right)$, where $\sigma_{n}$ is the noise standard deviation, which is another free parameter to be estimated. 
Our formulation of the GP model also implies that the differences between the observed values of DBH and the predicted values also follow the same GP model, albeit with the constant zero mean (Rasmussen and Williams, 2006). In other words, the mean value of the $\mathrm{DBH}$ for a new tree can be derived from the training tree $\mathrm{DBH}$ values, as soon as kernel $K$ is found. Thus, our Gaussian process regression model is controlled by a vector of free hyperparameters $\theta=\left\{\sigma, \sigma_{n}, w_{1}, \ldots, w_{P}\right\}$.

With all necessary pieces of information in place, $\theta$ and $d *$ can be found using the maximum-likelihood (ML) principle. Given the assumptions of our model, the log likelihood maximized with respect to $\theta$ is a Gaussian likelihood

$$
\log p(d \mid X, \theta)=-\frac{1}{2} d^{T} K_{d}^{-1} d-\frac{1}{2} \log \left|K_{d}\right|-\frac{N t r}{2} \log 2 \pi
$$

where $K_{d}=K+\sigma_{n I}^{2}$, and $K$ is the matrix of training tree DBH covariances. The first term increases with a better fit to the available training tree data, whereas the second term penalizes our regression model for complexity. In this way, the ML estimation for the GP model also acts as a covariance model selection procedure aimed at minimizing the risk of overfitting the model. The Gaussian likelihood can have multiple local maxima, and therefore the ML estimation requires setting initial values for the hyperparameters. In our experiment, the following initial values were used: $\sigma=1 ; \sigma_{n}=0.1$, and $w_{p}=1$.

Using the obtained ML estimate of $\theta$, the DBH values were found $\left(K_{*}\left[K+\sigma_{n}^{2} I\right]^{-1} d\right)$, which is the mean value of the DBH posterior distribution (see Gibbs (1998) for further details). 


\subsubsection{Tree classification}

When a Gaussian process approach is applied to a two-class classification problem, the target random variable is a discrete class label $y=\{0,1\}$. Given a vector of ALS metrics $x$, the class label assignment by GP classification requires modeling the tree posterior probability for one of the classes, which we denote by $p(x)$.

For each classification problem, we selected ALS metrics that maximize inter-class and minimize within-class differences in the training data. For the snag/alive classification problem, these metrics included 12 ALS metrics: five structural metrics (minimum height, height coefficient of variation, fractional cover, volume, and area) and seven intensity metrics (maximum, minimum, median, variance, coefficient of variation, and accumulated corrected intensity). For hardwood/conifer classification, we used nine metrics, including seven structural metrics (maximum, median, standard deviation, and skewness of heights; fractional cover, volume, area) and two intensity metrics (minimum intensity and accumulated intensity normalized by area). As in the case of regression (sect. 2.8.1), all ALS-metrics were normalized to fit the interval between 0 and 1 . Our training sample for snag/live classification included 497 trees measured in the field (sect. 2.3), and for conifer vs. hardwood snag problem 343 training trees were used.

Conceptually, the posterior probability estimation proceeds in two steps (Rasmussen and Williams, 2006). First, a GP regression approach with the squared exponential kernel for the covariance function (as in sect. 2.8.1) is used to map the ALS feature vector $x$ into an intermediate one-dimensional latent random variable $z=f(x)$. This 
latent variable, in effect, models relative likelihood of class membership as a stochastic function $f$ of the feature vector $x$. The second step is to apply a deterministic sigmoid function transforming $z$ from its native domain into the range between 0 and 1 , so that it can be viewed as the class probability. In this work we used the Gaussian cumulative distribution function, $\Phi(z)$, also called the error function.

The parameters of the GP model for classification include $\sigma$, and $w_{1}, \ldots, w_{P}$, where $\mathrm{P}$ is the number of ALS metrics. In each classification problem, the maximumlikelihood estimation of the parameters was performed via the Expectation Propagation (EP) algorithm (Minka, 2001; Rasmussen and Williams, 2006), with $\sigma$ and all weight $w_{p}$ initialized to 1 .

\subsection{Black-backed Woodpecker habitat mapping}

Based on conifer snag basal area across Black-backed Woodpecker home ranges studied by Tingley et al. (2014), we mapped contiguous areas with potential (i.e., snag basal area $>$ the lowest mean basal area observed across any Black-backed Woodpecker home range) or optimal (i.e., snag basal area $>$ the 50th percentile of average basal area values observed across any Black-backed Woodpecker home range) Blackbacked Woodpecker habitat. To estimate the accuracy of the resulting overall basal area mapping, we compared the measured and mapped conifer snag basal area over the field plots. Finally, we estimated the total potential and optimal habitat area and assessed its degree of fragmentation. 
330

331

\section{Results}

\subsection{Tree detection}

Our results show that the percentage of detected trees varies with its stem diameter (Table 2). The algorithm detected $99 \%$ of trees with large stem diameter with only commission errors and $75 \%$ of trees with medium stem diameters (Table 2). Note that $25 \%$ of medium size trees remained undetected, because they were suppressed by larger trees. The algorithm detected $87 \%$ of trees with stem diameter larger than $30 \mathrm{~cm}$. The inability to detect suppressed trees is a well-known drawback of CHMbased tree delineation algorithms. Although the small trees objectively represent the greatest challenge, we have been able to map nearly $40 \%$ of them.

\subsection{Classification and stem diameter estimation results}

\subsubsection{Snag/live classification}

The results presented in Table 3 demonstrate high accuracy of snag/live classification, with the overall correct classification rate of $91.8 \%$ and a kappa coefficient of 0.84 . Both, commission and omission errors are under $10 \% \pm 3 \%$, based on the LPO cross-validation (Table 3).

The model relies on the coefficient of variance (CV) as the only metric related with heights. Intensity data is used in the model through the maximum, variance, coefficient of variation, with $\mathrm{CV}$ as the most relevant one for the model. Finally, 
the model uses shape related metrics, mostly area but also volume to discriminate between classes (Figure 3).

Figure 4 shows how the snags distribution aligns with the burned area in Figure 2, where moderate and high severity sites correspond to partial and complete tree mortality, respectively. Figure 4 also shows how live trees abound at higher elevations.

\subsubsection{Conifer/Hardwood classification}

Similar to snag/live classification, the Gaussian process technique effectively discriminates between snag hardwood and conifer trees. Table 4 shows, based on the LPO cross-validation, that the correct classification rates for both classes are very similar and approach $85 \%$, with std of $5 \%$. The kappa coefficient for the snag type classification is 0.64 . Both, commission and omission errors are under $16 \% \pm 5 \%$.

Both maximum and median heights have a relevant role in the classification since conifer snags tend to stand taller. The minimum value of intensity clearly has an impact on the classifier. In terms of metrics related to height, the standard deviation, skewness, and fractional cover are also relevant for the model. The analysis shows that conifer snags can reach larger values of standard deviation and fractional cover than dead hardwoods. Finally, the model also uses the area metric to separate between classes (Figure 3).

Snag maps by forest type (Figure 4) show that hardwoods are somewhat distributed across the study site, whereas conifers exhibit more apparent spatial clustering, 
mainly south-east and central areas of Stanislaus National Forest and much of the burned portion of Yosemite National Park.

\subsubsection{DBH estimation results}

Our results show that the Gaussian process regression provides an effective method to estimate stem $\mathrm{DBH}$ from maximum height and area, with the determination coefficient $R^{2}=0.81$ and rmse $=10.6 \mathrm{~cm}$. The model performs similarly for medium and large stem trees, as seen from the scatter plot of true versus GPR-predicted stem diameter for 119 snag conifer trees in Figure 5. Table 5 provides more information about estimation accuracy per tree size class. For small trees, the absolute errors are smaller, however the relative rms error (Table 5) is larger than for the other two size classes. The use of relative error is more appropriate to understand the performance of the model per tree size class, particularly for medium and large trees, since it is not affected by the size of the stem itself. Medium and large trees are more important for Black-backed Woodpecker foraging habitat than small trees, and therefore, better accuracy of our model for medium and large trees is an advantage. Stem diameters for small trees tend to get underestimated with the GP modeling, while no significant bias is observed for medium trees (Figure 5).

The GP-based estimation results provide a significant improvement over the traditional DBH modeling approach based on allometric equations (Keyser and Dixon, 2008). The allometric model has a lower $R^{2}$ value (0.73) and larger scatter, as shown

in Figure 5. Furthermore, the errors of the GP estimation are reduced by almost a 
half, with respect to the allometric approach $(\mathrm{rmse}=16.5 \mathrm{~cm}$ and relative error $=$ $43.5 \%$ ), thus providing a more accurate input into deriving basal area calculation. Conifer snags basal area-weighted mean tree diameter map (Figure 4) showed how large DBH trees dominate at the highest elevations within Yosemite National Park and the north-west area of the Rim Fire within Stanislaus National Forest.

\subsection{Black-backed Woodpecker habitat mapping results}

Optimal and potential habitat for Black-backed Woodpecker comprise $53.7 \mathrm{~km}^{2}$ and $58.4 \mathrm{~km}^{2}$, respectively, representing 5.1 and $5.6 \%$ of the overall footprint of the Rim Fire. In many instances, optimal habitat areas are adjacent to or surrounded by areas mapped as potential habitat, resulting in relatively large patches of apparent habitat. Some of the larger habitat patches are localized near the center of the burned area on Stanislaus National Forest, and to the east, near the border with Yosemite National Park. These large fragments comprise approximately $1 \mathrm{~km}^{2}$ each, whereas most of the other optimal habitat areas, particular in Yosemite National Park, are more highly fragmented. Comparing the measured and mapped conifer snag basal area over the field plots showed that our method mapped $81.3 \% \pm 18.7 \%$ of the total basal area (Figure 6). Our estimates of the extent of potential and optimal Black-backed Woodpecker habitat in the Rim Fire should therefore be considered lower bounds. 
410

\section{Discussion}

Large stem diameter trees are detected at markedly higher rates than those with small diameter stems, likely because small trees are commonly suppressed by larger overstory trees and thus are mostly undetectable by LiDAR. This result is in agreement with previous studies (Solberg et al., 2006; Chen et al., 2006; Reitberger et al., 2009; Duncanson et al., 2014). Although under-detection of small trees leads to underestimation of basal area, we believe the impact of this error on Black-backed Woodpecker habitat mapping evaluation is minimal, due to the species preference for medium and large snags for foraging. Additionally, the contribution of large and medium stems to the basal area estimation in our field plots is $36 \%$ and $48 \%$ respectively, what reinforces the small impact of undetected small trees in our work. Nevertheless, if our method is also to be applied for wildlife species that utilize smaller diameter snags, it should include additional steps to refine the Watershed Segmentation algorithm output. Examples of successful such post-segmentation refinement steps can be found in Reitberger et al. (2009) and Duncanson et al. (2014).

A common factor determining the accuracy of all tree detection approaches is the ALS data point density. Our method used a high-density ALS dataset, averaging 19 points per $m^{2}$. While a lower density data would negatively impact detection rates for both live and snag trees, the impact on snags would be more dramatic, because small objects like snags may no longer have a minimal number of returns to form a separate segment. Indeed, even with our high-density data, our snags often provide

just a few above-ground returns, with fewer hits when defoliated (e.g. $<10$ ). The 
mean number of canopy ALS points per segment was $454 \pm 552$. We expect that lower density might also have a negative impact on the classifications, and DBH estimation.

The main advantages of using Gaussian processes include the probabilistic, interpretable outputs and uncertainty information, and a built-in mechanism for automatic selection of relevant metrics based on the covariance kernel weights. Not surprisingly, our results suggest that the chosen ALS metrics related to return intensity are highly informative for snag identification (see Figure 3, top graph). These metrics include maximum (Max-I), coefficient of variation (CV-I), and variance (Var-I). Indeed, metrics CV-I and Var-I are meaningful as they tend to have lower values for live trees than for snags; whereas maximum intensity is expected to be lower for snags. This high contribution of intensity-related metrics is in agreement with other studies (Kim et al., 2009; Korpela et al., 2010) that relate lower intensity with snags, for which returns are based on reflections from burned stem and branches. However, it contradicts the work of Yao et al. (2012), who found intensity metrics only moderately important to detect $71 \%$ of snags under leaf-off conditions. The importance of the canopy penetration metric in the model of Yao et al. (2012) is consistent with the relevance of fractional cover in our results. It should be noted that fractional cover is not always enough to differentiate snags from live trees. Similar fractional cover values can correspond to snag and live conifer because conifer snags often retain dead needles. However, in cases in which the snags have completely lost their foliage they effectively relate to low fractional cover values. Consistent with our results, the variability of heights have been found useful to identify snags using area-based 
approaches (Martinuzzi et al., 2009; Bater et al., 2009). For example, Martinuzzi et al. (2009) presents detection rates of $86 \%$ to $88 \%$ for different diameter classes using height and topography-related metrics with a plot-based approach, but only when additional forest successional data are used. Our snag detection rate is also higher than that of Wing et al. (2015), who present an overall detection of $56 \%$ for stem diameters larger than $25 \mathrm{~cm}$.

Separation of conifer and hardwood snags, relied primarily on height-related metrics, mainly the median but also the maximum and standard deviation. The importance of both maxima and median heights are explained from the fact that conifer snags tend to stand taller. The area occupied by the snag and its fractional cover are also relevant for the model (Figure 3). The data show that conifer snags on average have larger values of standard deviation of height and fractional cover than dead hardwoods, with values in common for both classes. This might be due to the fact that conifer snags might retain brown needles and therefore have large fractional cover and standard deviation, whereas dead hardwood have lost their foliage and have lower values in both metrics.

The arrangement of the canopy, depending on forest type, has been successfully related to intensity (Kim et al., 2009; Ørka et al., 2010). Some studies found the average of intensities to be less for conifers than for hardwoods (García et al., 2010; Vauhkonen et al., 2014). In our study both forest types are dead and unsurprisingly intensity plays a minor role in the classifier. However, we note that lower values of the minimum intensity characterize conifer snags which is in agreement with Vauhkonen et al. (2014) and García et al. (2010). Our classifier has an overall accuracy of 
$84.8 \%$. This result is comparable with studies that classify live conifers from leafoff hardwoods such as Kim et al. (2009) who achieved a classification accuracy of $83.4 \%$. It must be noted that some snags in our samples were pole-shaped $(3.7 \%$ of our measured trees), which are difficult or impossible to differentiate.

Our estimation of stem diameters for conifer snags using Gaussian process regression proved reliable and comparable with other studies in terms of the correlation coefficient (Popescu, 2007; Yao et al., 2012); however, the rmse is larger than expected (Table 5). Popescu (2007) for example, estimated stem diameter with a rmse of 4.9 cm while Muss et al. (2011) even though estimating DBH with lower coefficient of correlation that our results, had lower rmse. It must be noted that in those studies trees are alive, whereas in our case broken or partially consumed snags introduced noise into the model. Furthermore, our field data had similar stem diameters for very different tree heights. In general, the method overestimates very large stem diameters $(>90 \mathrm{~cm})$ while large and medium diameter trees are estimated with no significant bias (Figure 5 and Table 5). Nevertheless, our Gaussian process-based method provides a significant improvement over the traditional use of site-specific conifer allometric equations (Figure 5). The presented method for mapping conifer snag basal area represents a chain of steps, each of which factoring in the accuracy of the final map and any derived metrics of habitat mapping, such as the ones discussed in sect 3.3. Furthermore, the combined effect of tree delineation error, confusion in snag/live and conifer/hardwood classifications, and the DBH modeling residuals on the final product, is also expected to vary with the forest density and gap structure, species composition, and other factors. 
Although ALS accommodates the extraction of relevant 3D structural metrics at different level of details, its potential in wildlife studies is not being fully exploited if detailed habitat attributes are not derived at grain sizes known to be relevant to conservation and management (Müller and Brandl, 2009). One of the main advantages of the presented methodology is the use of a single-tree approach that enabled the aggregation of estimated basal area at the scale required by the habitat model without loss of information. This would not be the case for area-based estimations that, if rescaled, will introduce an unknown impact into habitat modelling results (Garabedian et al., 2014). In addition, home ranges are not homogeneous (Tingley et al., 2014) and a single tree approach provides the flexibility of aggregated results in different spatially discriminant shapes.

Credible assessments of habitat for indicator species or species of management concern can help land managers make difficult decisions about which burned stands to harvest or which to retain for wildlife habitat. This model-based approach is particularly useful for Black-backed Woodpecker, which may not fully colonize new burned areas until many months (or even multiple years) after the fire. On-the-ground occupancy surveys conducted on this timeline may be too late to inform decisions about post-fire forest management. In contrast, when suitable ALS data is available, predicted habitat can be mapped rapidly, as required by land managers who need to act while fire-killed trees are still merchantable.

The methodology presented provides an effective way to detect and identify snags at the single-tree level and characterize their type and size with uncertainty estimations using only high-density ALS data. Furthermore, it provides wall-to-wall coverage of 
predicted habitat for the Black-backed Woodpecker across the full extent of a recent megafire. Black-backed Woodpeckers are strongly associated with habitat conditions created by mid- and high-severity fires. Our habitat map provides a tool that land managers can use for identifying forest stands that, if left unharvested, are likely to be of greatest value to Black-backed Woodpeckers. We caution, however, that managing habitat for one wildlife species that is strongly associated with recently burned forest (or any other habitat) does not necessarily ensure that the needs of all such species will be met (Landres et al., 1988).

The maps generated can be used as a base layer to improve habitat modeling at broad scales (Tingley et al., 2014) as well as an exploratory tool to study structural patterns in combination with occupancy or biodiversity data (Vierling et al., 2008). Overall, the methodology presented can be used in a variety of applications related to biodiversity, environmental health and vegetation dynamics studies, such as quantifying tree mortality attributed to increases in temperature and drought or forests affected by insect infestation. In postfire scenarios, a snag map can be used to improve burn severity estimation (Gajardo et al., 2014), precise location of green islands for reseeding, and as a baseline for future assessment of vegetation regeneration after fire (Abella and Fornwalt, 2014). Finally, the classification of snags by its forest type and its diameter size estimation can be applied in dead biomass retrieval studies (Kim et al., 2009). Dead biomass estimation is compelling in a climate change context, given the critical role burned trees play in carbon sequestration, retaining carbon for decades, and releasing it gradually by decomposition (Siccama et al., 2007). 


\section{Conclusion}

Our study shows the utility of high-density discrete ALS data for mapping the mortality status, type, and stem diameter of trees in a recently burned forest. These maps, in conjunction with habitat models based on snag abundance and characteristics, allow identification of habitat for Black-backed Woodpecker and other wildlife species. This work contributed to developing a fast and efficient operational methodology to characterize the extent of burned forest at the tree level, which can greatly aid wildlife habitat assessment, forest management, and conservation planning after megafires. Timely, spatially distributed characterization of burned forest will become increasingly important in light of projected increase in megafire frequency. A potential avenue for future development would involve the identification of hotspots for multiple snag-dependent taxa within the same burned landscape, allowing an integrated, multi-species approach to forest management and species conservation.

\section{Acknowledgments}

This research was carried out within the ambit of the project Multi-sensor remote sensing study of California's Rim Fire to inform post-fire ecosystem restoration and effective prevention of future catastrophic wildfires. Sponsor: USFS. Mariano Garcia is supported by the Marie Curie IOF (ForeStMap - 3D Forest Structure Monitoring and Mapping, Project Reference: 629376). The contents on this paper reflect only the authors views and not the views of the European Commission. We greatly appreciate the help of Mitzi Thornley and the Science Division Yosemite National Park for the permission to conduct research in Yosemite National Park (YOSE00653/YOSE-2014-SCI-0124). 
569

\section{References}

Abella, S. R. and P. J. Fornwalt (2014). Ten years of vegetation assembly after a North American mega fire. Global Change Biology 21, 789-802.

Ackers, S. H., R. J. Davis, K. A. Olsen, and K. M. Dugger (2015). The evolution of mapping habitat for northern spotted owls (Strix occidentalis caurina): A comparison of photo-interpreted, Landsat-based, and lidar-based habitat maps. Remote Sensing of Environment 156, 361-373.

Bater, C. W., N. C. Coops, S. E. Gergel, V. LeMay, and D. Collins (2009). Estimation of standing dead tree class distributions in northwest coastal forests using lidar remote sensing. Canadian Journal of Forest Research 39(6), 1080-1091.

Bergen, K. M., S. J. Goetz, R. O. Dubayah, G. M. Henebry, C. T. Hunsaker, M. L. Imhoff, R. F. Nelson, G. G. Parker, and V. C. Radeloff (2009). Remote sensing of vegetation 3-D structure for biodiversity and habitat: Review and implications for lidar and radar spaceborne missions. Journal of Geophysical ResearchBiogeosciences 114, 2005-2012.

Beucher, S. and C. Lantuéjoul (1979). Use of watersheds in contour detection. In International workshop on image processing: Real-time edge and motion detection/estimation.

Bradbury, R. B., R. A. Hill, D. C. Mason, S. A. Hinsley, J. D. Wilson, H. Balzter, G. Q. A. Anderson, M. J. Whittingham, I. J. Davenport, and P. E. Bellamy (2005). Modelling relationships between birds and vegetation structure using airborne lidar data: a review with case studies from agricultural and woodland environments. Ibis $147(3), 443-452$.

Brandtberg, T. (2007). Classifying individual tree species under leaf-off and leaf-on conditions using airborne lidar. ISPRS Journal of Photogrammetry and Remote Sensing 61(5), 325-340.

Bright, B. C., A. T. Hudak, R. McGaughey, H.-E. Andersen, and J. Negron (2013). Predicting live and dead tree basal area of bark beetle affected forests from discretereturn lidar. Canadian Journal of Remote Sensing 39, S99-S111.

Bütler, R., P. Angelstam, P. Ekelund, and R. Schlaepfer (2004). Dead wood threshold values for the three-toed woodpecker presence in boreal and sub-Alpine forest. Biological Conservation 119(3), 305-318. 
Bütler, R., P. Angelstam, and R. Schlaepfer (2004). Quantitative snag targets for the three-toed woodpecker Picoides tridactylus. Ecological Bulletins, 219-232.

Cade, B. S. (1997). Comparison of tree basal area and canopy cover in habitat models: Subalpine forest. The Journal of wildlife management, 326-335.

Chen, Q., D. Baldocchi, P. Gong, and M. Kelly (2006). Isolating individual trees in a savanna woodland using small footprint lidar data. Photogrammetric Engineering 6 Remote Sensing 72(8), 923-932.

Clawges, R., K. Vierling, L. Vierling, and E. Rowell (2008). The use of airborne lidar to assess avian species diversity, density, and occurrence in a pine/aspen forest. Remote Sensing of Environment 112(5), 2064-2073.

Daily, G. C., P. R. Ehrlich, and N. M. Haddad (1993). Double keystone bird in a keystone species complex. Proceedings of the National Academy of Sciences of the United States of America 90(2), 592-594.

Davenport, I. J., R. B. Bradbury, G. Q. A. Anderson, G. R. F. Hayman, J. R. Krebs, D. C. Mason, J. D. Wilson, and N. J. Veck (2000). Improving bird population models using airborne remote sensing. International Journal of Remote Sensing 21(13-14), 2705-2717.

Dudley, J. G., V. A. Saab, and J. P. Hollenbeck (2012). Foraging-habitat selection of Black-backed Woodpeckers in forest burns of southwestern Idaho. The Condor $114(2), 348-357$.

Duncanson, L. I., B. D. Cook, G. C. Hurtt, and R. O. Dubayah (2014). An efficient, multi-layered crown delineation algorithm for mapping individual tree structure across multiple ecosystems. Remote Sensing of Environment 154, 378-386.

Farley, G. H., L. M. Ellis, J. N. Stuart, and N. J. Scott (1994). Avian species richness in different-aged stands of riparian forest along the middle Rio Grande, New Mexico. Conservation Biology 8(4), 1098-1108.

Ferster, C. J., N. C. Coops, and J. A. Trofymow (2009). Aboveground large tree mass estimation in a coastal forest in British Columbia using plot-level metrics and individual tree detection from lidar. Canadian Journal of Remote Sensing 35(3), $270-275$.

Flannigan, M., B. Stocks, M. Turetsky, and M. Wotton (2009). Impacts of climate change on fire activity and fire management in the circumboreal forest. Global Change Biology 15(3), 549-560. 
Gajardo, J., M. García, and D. Riaño (2014). Applications of Airborne Laser Scanning in Forest Fuel Assessment and Fire Prevention, Volume 27 of Managing Forest Ecosystems, pp. 439-462.

Garabedian, J. E., R. J. McGaughey, S. E. Reutebuch, B. R. Parresol, J. C. Kilgo, C. E. Moorman, and M. N. Peterson (2014). Quantitative analysis of woodpecker habitat using high-resolution airborne lidar estimates of forest structure and composition. Remote Sensing of Environment 145, 68-80.

García, M., D. Riaño, E. Chuvieco, and F. M. Danson (2010). Estimating biomass carbon stocks for a Mediterranean forest in central Spain using lidar height and intensity data. Remote Sensing of Environment 114(4), 816-830.

Gibbs, M. N. (1998). Bayesian Gaussian processes for regression and classification. Ph. D. thesis, University of Cambridge.

Goetz, S., D. Steinberg, R. Dubayah, and B. Blair (2007). Laser remote sensing of canopy habitat heterogeneity as a predictor of bird species richness in an eastern temperate forest, USA. Remote Sensing of Environment 108(3), 254-263.

Graf, R. F., L. Mathys, and K. Bollmann (2009). Habitat assessment for forest dwelling species using lidar remote sensing: Capercaillie in the Alps. Forest Ecology and Management 257(1), 160-167.

Höfle, B., M. Hollaus, H. Lehner, N. Pfeifer, and W. Wagner (2008). Area-based parameterization of forest structure using full-waveform airborne laser scanning data. Proceedings of SilviLaser 2008, 227-235.

Holmgren, J. and Å. Persson (2004). Identifying species of individual trees using airborne laser scanner. Remote Sensing of Environment 90(4), 415-423.

Hudak, A. T., B. C. Bright, J. Negron, R. McGaughey, H.-E. Andersen, and J. A. Hicke (2012, September). Predicting live and dead tree basal area in bark beetleaffected forests from discrete-return lidar. Vancouver, Canada. SilviLaser.

Hyde, P., R. Dubayah, W. Walker, J. B. Blair, M. Hofton, and C. Hunsaker (2006). Mapping forest structure for wildlife habitat analysis using multi-sensor (LiDAR, SAR/inSAR, ETM , quickbird) synergy. Remote Sensing of Environment 102(12), 63-73.

Kaasalainen, S., T. Lindroos, and J. Hyyppa (2007). Toward hyperspectral lidar: measurement of spectral backscatter intensity with a supercontinuum laser source. Geoscience and Remote Sensing Letters, IEEE 4(2), 211-215. 
Keyser, C. and G. Dixon (2008). Western Sierra Nevada (WS) variant overviewforest vegetation simulator. US Department of Agriculture, Forest Service, Forest Management Service Center, Fort Collins, CO (revised July 29, 2010).

Kim, S., R. J. McGaughey, H.-E. Andersen, and G. Schreuder (2009). Tree species differentiation using intensity data derived from leaf-on and leaf-off airborne laser scanner data. Remote Sensing of Environment 113(8), 1575-1586.

Kim, Y., Z. Yang, W. B. Cohen, D. Pflugmacher, C. L. Lauver, and J. L. Vankat (2009). Distinguishing between live and dead standing tree biomass on the North Rim of Grand Canyon National Park, USA using small-footprint lidar data. Remote Sensing of Environment 113(11), 2499-2510.

Korpela, I., H. O. Ørka, J. Hyyppä, V. Heikkinen, and T. Tokola (2010). Range and AGC normalization in airborne discrete-return lidar intensity data for forest canopies. ISPRS Journal of Photogrammetry and Remote Sensing 65(4), 369-379.

Korpela, I., H. O. Ørka, M. Maltamo, T. Tokola, J. Hyyppä, et al. (2010). Tree species classification using airborne lidar-effects of stand and tree parameters, downsizing of training set, intensity normalization, and sensor type. Silva Fennica 44(2), 319-339.

Landres, P. B., J. Verner, and J. W. Thomas (1988). Ecological uses of vertebrate indicator species: a critique. Conservation biology 2(4), 316-328.

MacArthur, R. and J. W. MacArthur (1961). On bird species-diversity. Ecology 42(3), 594-\&.

Maltamo, M. and T. Gobakken (2014). Predicting Tree Diameter Distributions, pp. 177-191. Springer, Netherlands.

Martinuzzi, S., L. A. Vierling, W. A. Gould, M. J. Falkowski, J. S. Evans, A. T. Hudak, and K. T. Vierling (2009). Mapping snags and understory shrubs for a LiDAR-based assessment of wildlife habitat suitability. Remote Sensing of Environment $113(12), 2533-2546$.

Mason, D., G. Anderson, R. Bradbury, D. Cobby, I. Davenport, M. Vandepoll, and J. Wilson (2003). Measurement of habitat predictor variables for organism-habitat models using remote sensing and image segmentation. International Journal of Remote Sensing 24(12), 2515-2532.

Miller, J., H. Safford, M. Crimmins, and A. Thode (2009). Quantitative evidence for 
increasing forest fire severity in the Sierra Nevada and southern Cascade Mountains, California and Nevada, USA. Ecosystems 12(1), 16-32.

Miller, J. D. and A. E. Thode (2007). Quantifying burn severity in a heterogeneous landscape with a relative version of the delta Normalized Burn Ratio (dNBR). Remote Sensing of Environment 109(1), 66-80.

Minka, T. P. (2001). A family of algorithms for approximate Bayesian inference. Ph. D. thesis, Massachusetts Institute of Technology.

Moritz, M. A., E. Batllori, R. A. Bradstock, A. M. Gill, J. Handmer, P. F. Hessburg, J. Leonard, S. McCaffrey, D. C. Odion, T. Schoennagel, et al. (2014). Learning to coexist with wildfire. Nature 515(7525), 58-66.

Müller, J. and R. Brandl (2009). Assessing biodiversity by remote sensing in mountainous terrain: the potential of LiDAR to predict forest beetle assemblages. Journal of Applied Ecology 46(4), 897-905.

Müller, J. and R. Bütler (2010). A review of habitat thresholds for dead wood: a baseline for management recommendations in European forests. European Journal of Forest Research 129(6), 981-992.

Muss, J. D., D. J. Mladenoff, and P. A. Townsend (2011). A pseudo-waveform technique to assess forest structure using discrete lidar data. Remote Sensing of Environment 115(3), 824-835.

Nelson, R., C. Keller, and M. Ratnaswamy (2005). Locating and estimating the extent of Delmarva fox squirrel habitat using an airborne LiDAR profiler. Remote Sensing of Environment 96(3), 292-301.

Noss, R. F., J. F. Franklin, W. L. Baker, T. Schoennagel, and P. B. Moyle (2006). Managing fire-prone forests in the western United States. Frontiers in Ecology and the Environment 4 (9), 481-487.

Ørka, H. O., E. Næsset, and O. M. Bollandsås (2010). Effects of different sensors and leaf-on and leaf-off canopy conditions on echo distributions and individual tree properties derived from airborne laser scanning. Remote Sensing of Environment 114(7), 1445-1461.

Perona, P. and J. Malik (1990). Scale-space and edge detection using anisotropic diffusion. Pattern Analysis and Machine Intelligence, IEEE Transactions on 12(7), 629-639. 
Pesonen, A., O. Leino, M. Maltamo, and A. Kangas (2009). Comparison of field sampling methods for assessing coarse woody debris and use of airborne laser scanning as auxiliary information. Forest Ecology and Management 257(6), 15321541.

Pesonen, A., M. Maltamo, K. Eerikäinen, and P. Packalèn (2008). Airborne laser scanning-based prediction of coarse woody debris volumes in a conservation area. Forest Ecology and Management 255(8), 3288-3296.

Popescu, S. C. (2007). Estimating biomass of individual pine trees using airborne lidar. Biomass and Bioenergy 31 (9), 646-655.

Popescu, S. C. and M. Hauglin (2014). Estimation of biomass components by airborne laser scanning. In Forestry Applications of Airborne Laser Scanning, pp. 157-175. Springer.

Rasmussen, C. and C. Williams (2006). Gaussian processes for machine learning, vol. 1.

Reitberger, J., C. Schnorr, P. Krzystek, and U. Stilla (2009). 3D segmentation of single trees exploiting full waveform lidar data. ISPRS Journal of Photogrammetry and Remote Sensing 64(6), 561-574.

Riaño, D., F. Valladares, S. Condés, and E. Chuvieco (2004). Estimation of leaf area index and covered ground from airborne laser scanner (Lidar) in two contrasting forests. Agricultural and Forest Meteorology 124(3), 269-275.

Rota, C. T., J. J. Millspaugh, M. A. Rumble, C. P. Lehman, and D. C. Kesler (2014). The role of wildfire, prescribed fire, and mountain pine beetle infestations on the population dynamics of black-backed woodpeckers in the black hills, South Dakota. Plos One 9(4).

Sherrill, K., M. Lefsky, J. Bradford, and M. Ryan (2008). Forest structure estimation and pattern exploration from discrete-return lidar in subalpine forests of the central Rockies. Canadian Journal of Forest Research 38(8), 2081-2096.

Siccama, T. G., T. J. Fahey, C. E. Johnson, T. W. Sherry, E. G. Denny, E. B. Girdler, G. E. Likens, and P. A. Schwarz (2007). Population and biomass dynamics of trees in a northern hardwood forest at Hubbard Brook. Canadian Journal of Forest Research 37(4), 737-749.

Siitonen, J. (2001). Forest management, coarse woody debris and saproxylic or- 
ganisms: Fennoscandian boreal forests as an example. Ecological Bulletins (49), $11-41$.

Smart, L. S., J. J. Swenson, N. L. Christensen, and J. O. Sexton (2012). Threedimensional characterization of pine forest type and red-cockaded woodpecker habitat by small-footprint, discrete-return lidar. Forest Ecology and Management 281, 100-110.

Solberg, S., E. Næsset, K. H. Hanssen, and E. Christiansen (2006). Mapping defoliation during a severe insect attack on Scots pine using airborne laser scanning. Remote Sensing of Environment 102(3), 364-376.

Stephens, S. L., J. K. Agee, P. Z. Fule, M. P. North, W. H. Romme, T. W. Swetnam, and M. G. Turner (2013). Managing forests and fire in changing climates. Science 342(6154), 41-42.

Swatantran, A., R. Dubayah, M. Hofton, J. Blair, and L. Handley (2008). Mapping potential ivory billed woodpecker habitat using lidar and hyperspectral data fusion. In AGU Fall Meeting Abstracts, Volume 1, pp. 04.

Tarbill, G., P. Manley, and A. White (2015). Drill, baby, drill: the influence of woodpeckers on post-fire vertebrate communities through cavity excavation. Journal of Zoology 296(2), 95-103.

Tingley, M. W., R. L. Wilkerson, M. L. Bond, C. A. Howell, and R. B. Siegel (2014). Variation in home-range size of Black-backed Woodpeckers. Condor 116(3), 325340 .

Tingley, M. W., R. L. Wilkerson, C. A. Howell, and R. B. Siegel (2015). An integrated occupancy and home-range model to predict abundance of a wide-ranging, territorial vertebrate. Methods in Ecology and Evolution.

Vauhkonen, J., H. O. Ørka, J. Holmgren, M. Dalponte, J. Heinzel, and B. Koch (2014). Tree species recognition based on airborne laser scanning and complementary data sources. In Forestry applications of airborne laser scanning, pp. 135-156. Springer.

Vierling, K. T., L. A. Vierling, W. A. Gould, S. Martinuzzi, and R. M. Clawges (2008). Lidar: shedding new light on habitat characterization and modeling. Frontiers in Ecology and the Environment 6(2), 90-98.

Vogeler, J. C., A. T. Hudak, L. A. Vierling, J. Evans, P. Green, and K. I. T. Vierling 
(2014). Terrain and vegetation structural influences on local avian species richness in two mixed-conifer forests. Remote Sensing of Environment 147, 13-22.

Vogeler, J. C., Z. Yang, and W. B. Cohen (2015). Mapping post-fire habitat characteristics through the fusion of remote sensing tools. Remote Sensing of Environment.

Wing, B. M., M. W. Ritchie, K. Boston, W. B. Cohen, and M. J. Olsen (2015). Individual snag detection using neighborhood attribute filtered airborne lidar data. Remote Sensing of Environment 163, 165-179.

Yao, W., P. Krzystek, and M. Heurich (2012). Tree species classification and estimation of stem volume and dbh based on single tree extraction by exploiting airborne full-waveform LiDAR data. Remote Sensing of Environment 123, 368-380. 
TABLES

Table 1: ALS metrics used in the classifications and regression.

\begin{tabular}{ll} 
Metric name & Metrics description \\
\hline max h & Maximum height \\
min h & Minimum height \\
mean h $h$ & Mean height \\
mode h & Median height \\
std h & Modal height \\
var h & Variandard deviation of heights \\
cv h & Coefficient of variation of heights \\
skew h & Skewness of heights \\
kurt h & Kurtosis of heights \\
fC & Fractional cover \\
Vol & Volume \\
max i & Maximum intensity \\
min i & Minimum intensity \\
mean i & Mean intensity \\
med i & Median intensity \\
mode i & Modal intensity \\
std i & Standard deviation of intensities \\
var i & Variance of intensities \\
cv i & Coefficient of variation of intensities \\
skew i & Skewness of intensities \\
kurt i & Kurtosis of intensities \\
area & Area \\
cum i & Accumulated intensity \\
cumCorr i & Corrected accumulated intensity \\
&
\end{tabular}


Table 2: Individual tree detection accuracies for three DBH classes: small(10 to 30 $\mathrm{cm})$, medium $(30$ to $60 \mathrm{~cm}$ ), and large (greater than $60 \mathrm{~cm}$ ).

\begin{tabular}{lcccc} 
& All & Small & Medium & Large \\
\hline Commission.E.,\% & 12.3 & 10.4 & 8 & 17 \\
Omission.E,\% & 45.7 & 61.2 & 25 & 1 \\
\hline
\end{tabular}


Table 3: Confusion matrix for the snag/live classification. Values shown are the mean \pm std cross-validated results with 100 replications.

\begin{tabular}{l|l|cc|c} 
& \multicolumn{3}{|c|}{ Reference } & Total \\
\hline & & Snag & Live & \\
\hline GP & Snag & $96.9 \pm 6.8$ & $7.3 \pm 3.0$ & 104.2 \\
& Live & $10.1 \pm 3.1$ & $98.7 \pm 6.7$ & 108.8 \\
\hline \multirow{2}{*}{ Total } & 107 & 106 & 213 \\
& Producer's accuracy, $\%$ & $90.51 \pm 2.8$ & $93.1 \pm 2.8$ & \\
& User's accuracy, $\%$ & $93.04 \pm 2.7$ & $90.72 \pm 2.7$ & \\
\hline
\end{tabular}


Table 4: Confusion matrix for the conifers/hardwood classification. Values shown are the mean \pm std cross-validated results with 100 replications.

\begin{tabular}{l|l|cc|c} 
& & Reference & Total \\
\hline & & Conifer & Hardwoods & \\
\hline GP & Conifers & $62 \pm 5.6$ & $11.5 \pm 4$ & 73.5 \\
& Hardwoods & $11.4 \pm 3.7$ & $62.2 \pm 5.1$ & 73.6 \\
\hline & Total & 73.4 & 73.7 & 147 \\
& Producer's accuracy,\% & $84.5 \pm 5.0$ & $84.7 \pm 5.1$ & \\
& User's accuracy,\% & $84.5 \pm 5.0$ & $84.5 \pm 4.5$ & \\
\hline
\end{tabular}


Table 5: DBH estimation performance statistics, including mean error (ME), root mean-squared error (RMSE), mean absolute error (MEA) and relative error (RE) normalized by mean DHB. Error values shown are the mean \pm std over 100 replications.

\begin{tabular}{lcccc} 
GP regression & ME $(\mathrm{cm})$ & RMSE $(\mathrm{cm})$ & MAE $(\mathrm{cm})$ & RE $(\%)$ \\
\hline Small & $3.3 \pm 1.2$ & $7.2 \pm 1.4$ & $5.2 \pm 0.8$ & $20.3 \pm 2.1$ \\
Medium & $1.2 \pm 1.4$ & $8.7 \pm 1$ & $6.8 \pm 0.8$ & $16 \pm 1.9$ \\
Large 3 & $-5.4 \pm 2.6$ & $14.6 \pm 2.1$ & $11.2 \pm 1.5$ & $18.6 \pm 3.6$ \\
All & $0.01 \pm 1.2$ & $10.6 \pm 1$ & $7.6 \pm 0.6$ & $18.1 \pm 1.3$ \\
\hline
\end{tabular}

$R^{2}=0.81$ 


\section{FIGURES}

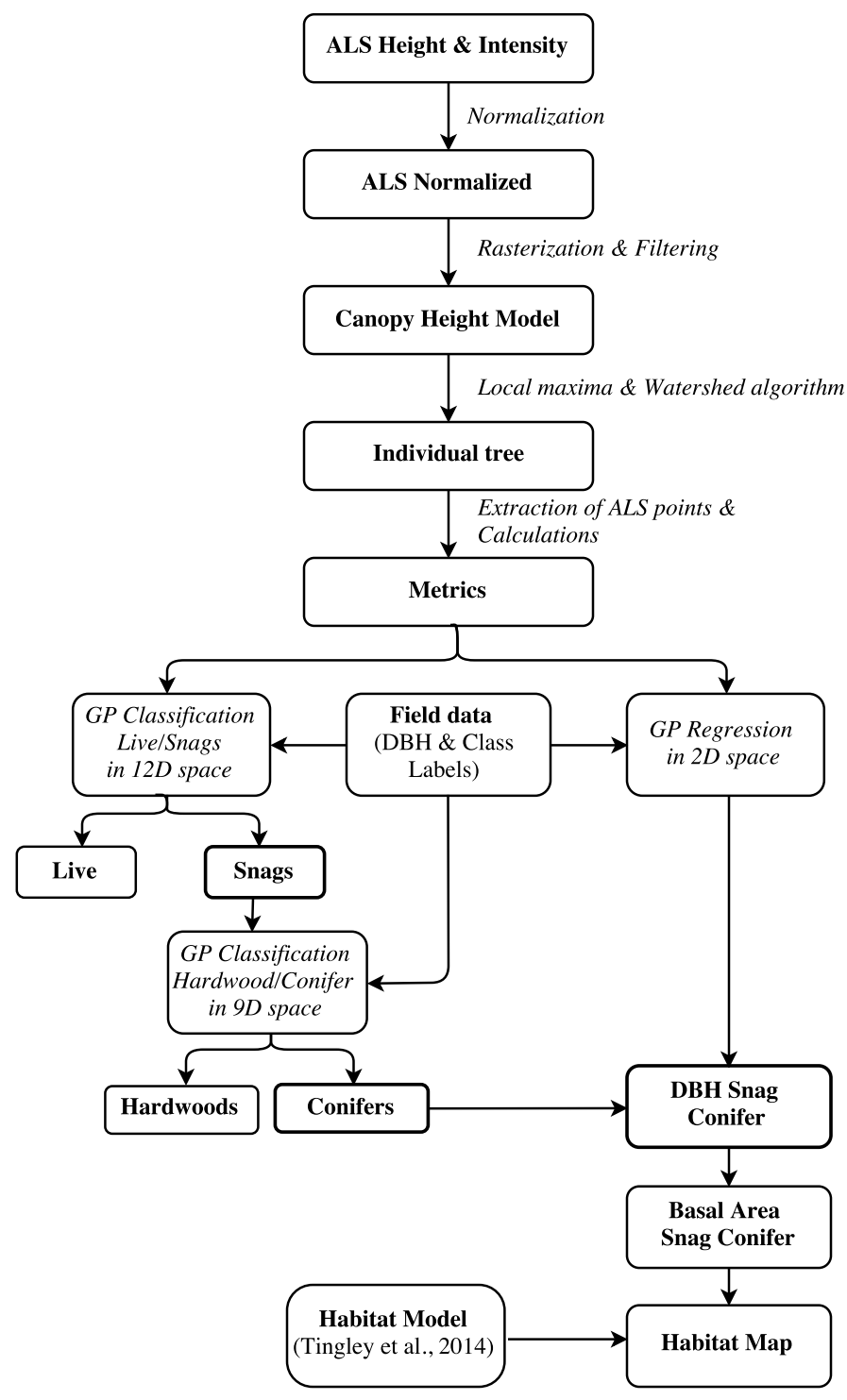

Figure 1: Workflow diagram for habitat mapping described in Sect. 2. 


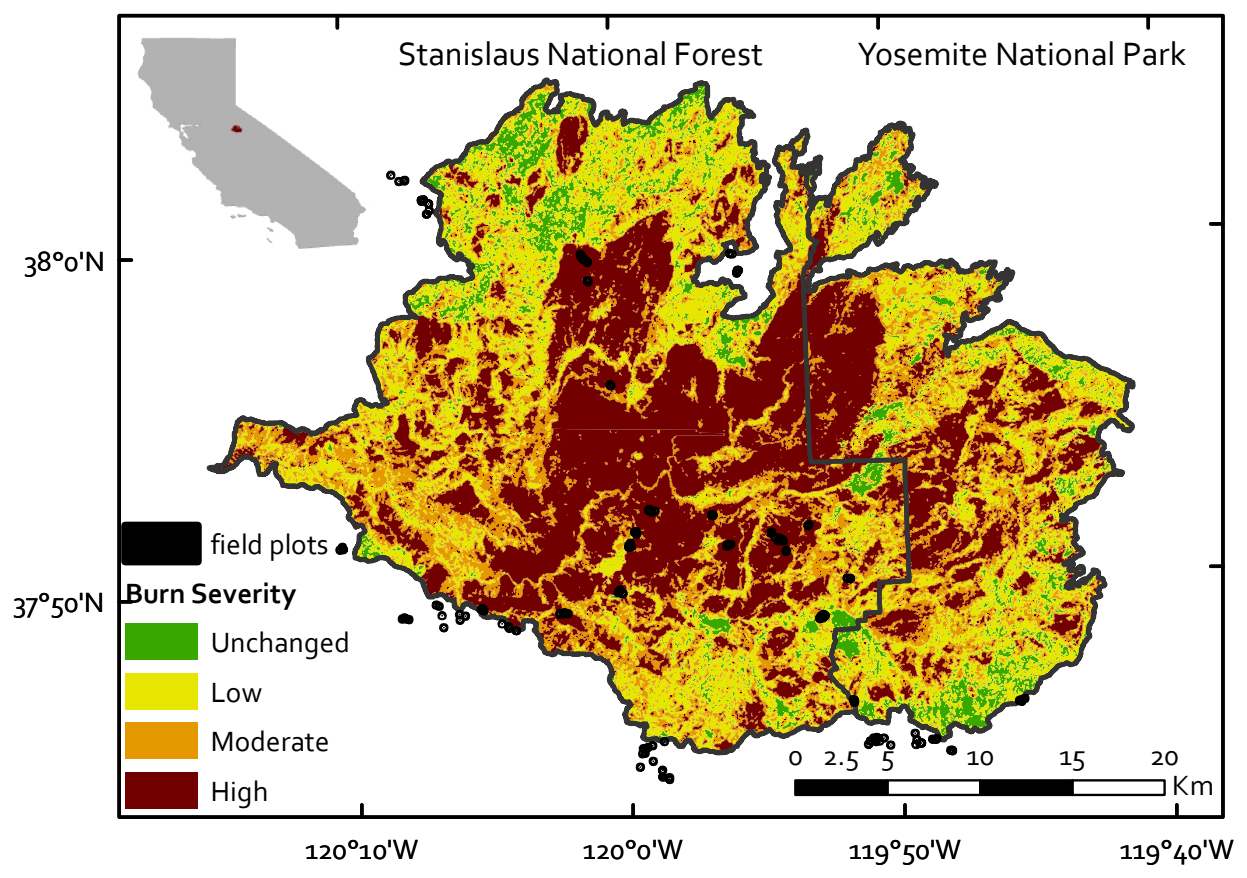

Figure 2: Location and Landsat-based bunn severity (\% change in canopy cover) of the 2013 Rim Fire on Stanislaus National Forest and Yosemite National Park (Miller and Thode, 2007) 

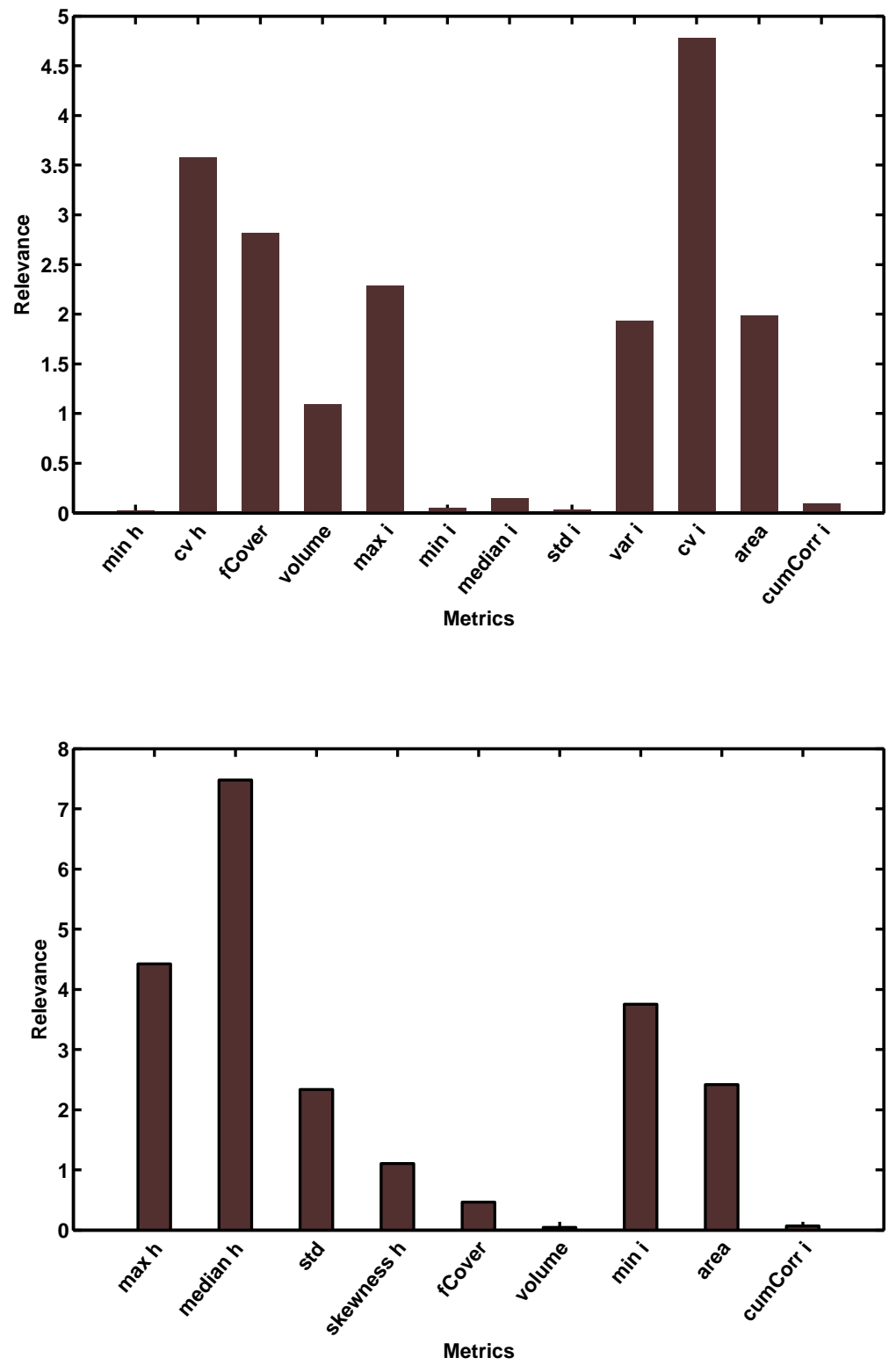

Figure 3: Relevance of the metrics in the GP snag/live (top) conifer/hardwood (bottom) model obtained from the non-negative weights $\left(w_{P}\right)$ of the kernel. 

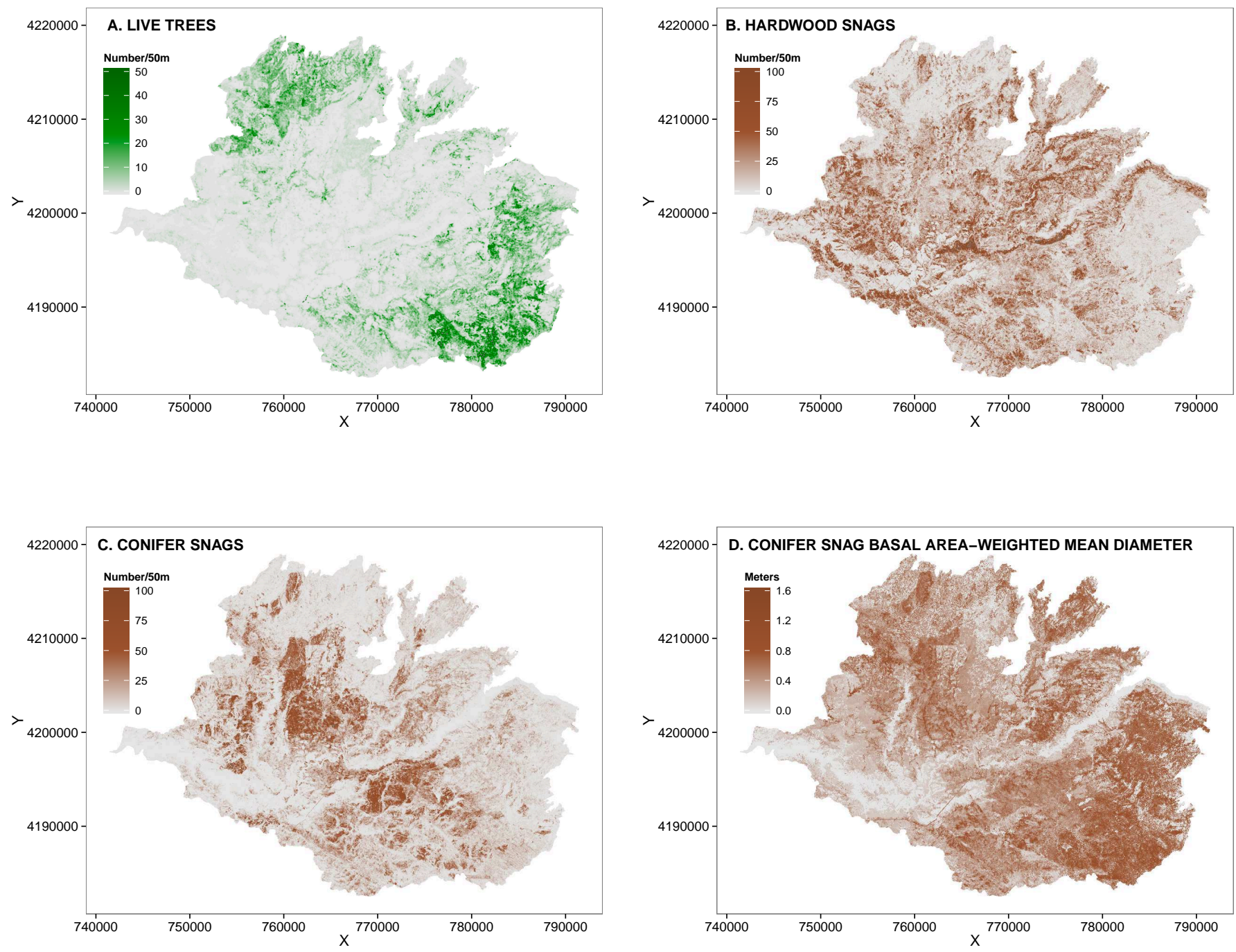

Figure 4: Number of live trees per pixel (A), number of hardwood snags (B), number of conifer snags $(\mathrm{C})$, and conifer snag basal area-weighted mean tree diameter, $\mathrm{m}(\mathrm{D})$. Pixel resolution $=50 \mathrm{~m}$. 

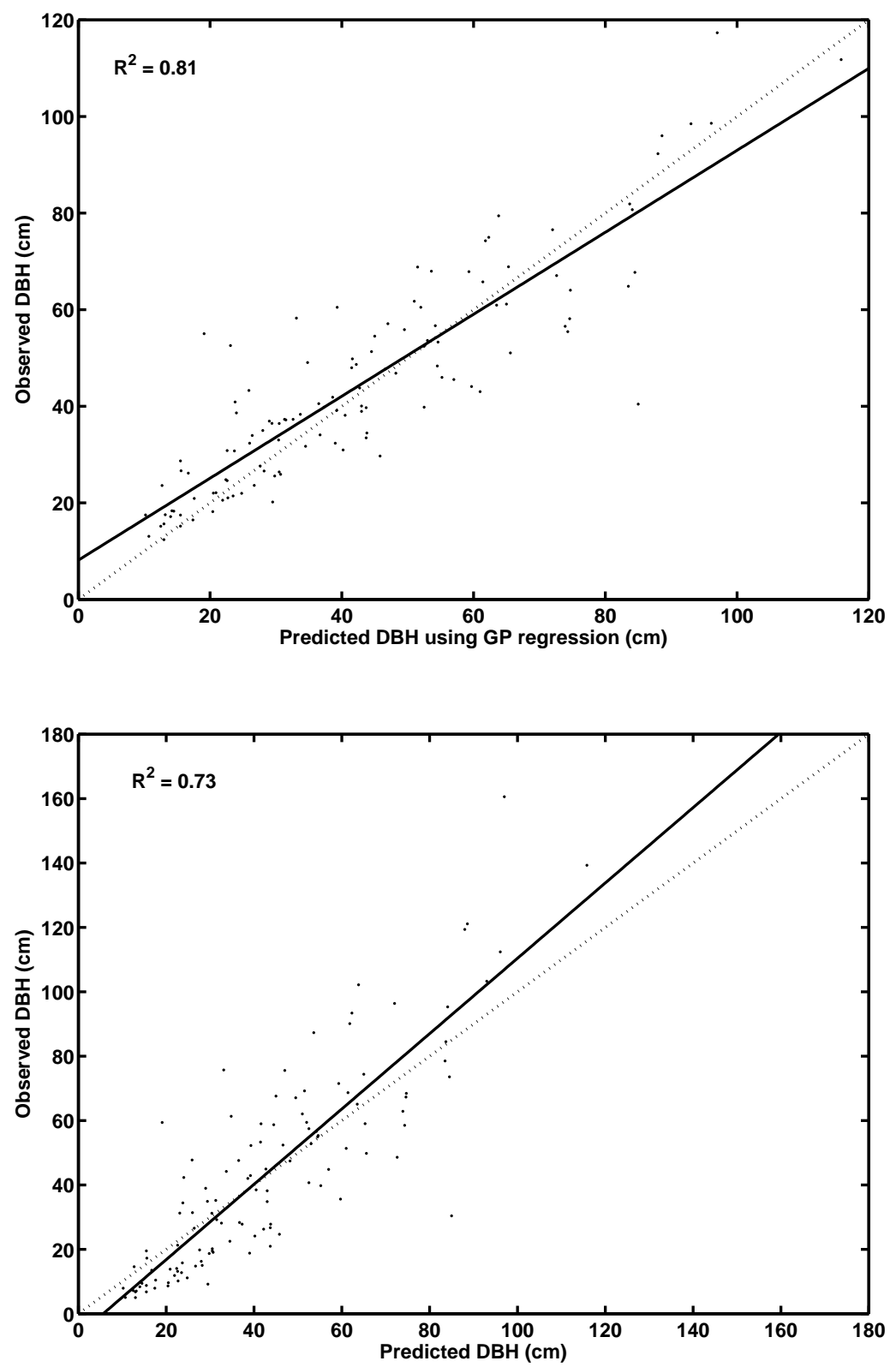

Figure 5: Scatterplot of observed and predicted conifer snag DBH using Gaussian process regression (top) and site-specific allometric equations for conifers (bottom). Solid lines show the least-squares linear relationship between the observed and predicted DBH. The 1:1 relationship is represented by a dashed line. 


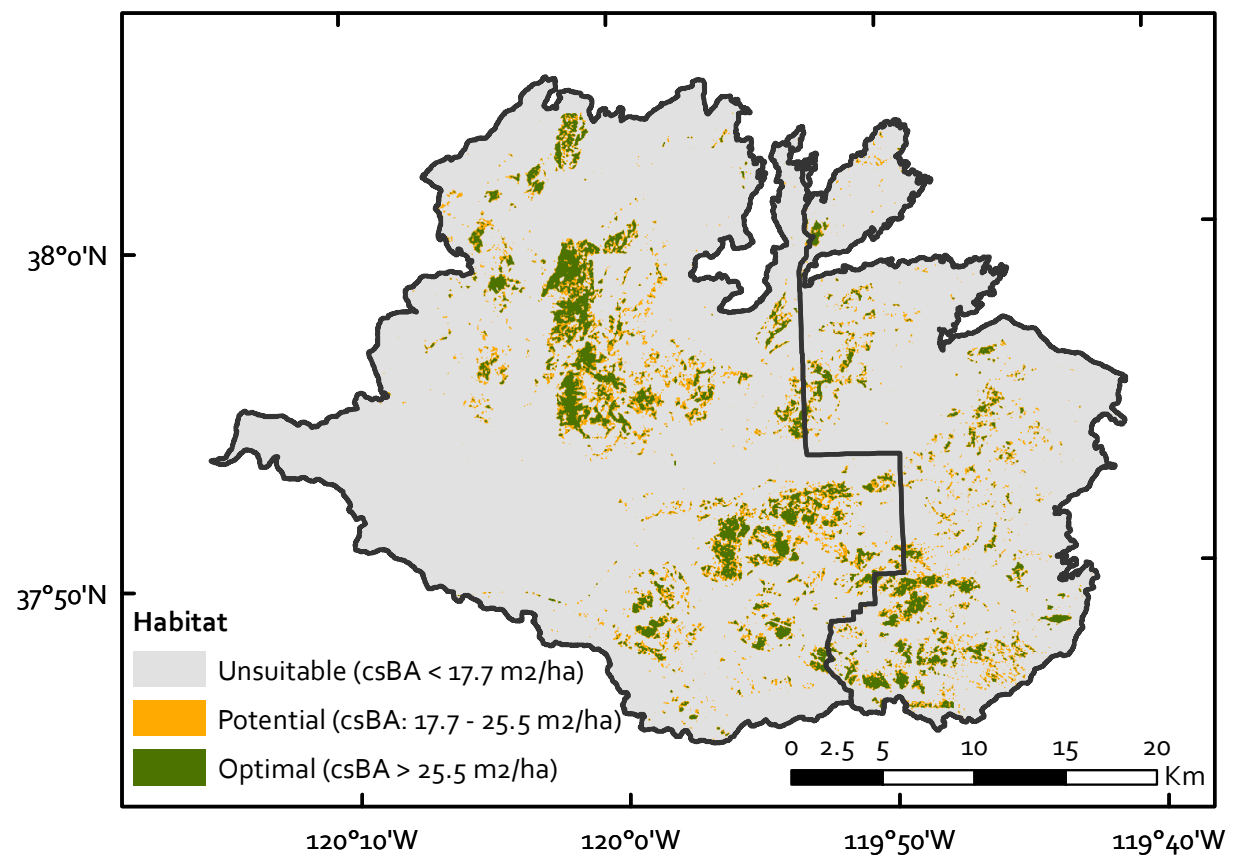

Figure 6: Habitat map for the Black-backed Woodpecker across the Rim Fire, based on pre-harvest conditions and conifer snag basal areas (csBA) thresholds obtained from Tingley et al. (2014). Pixel resolution $=20 \mathrm{~m}$. 